\title{
Urothelial carcinoma with prominent squamous differentiation in the setting of neurogenic bladder: role of human papillomavirus infection
}

\author{
Elen B Blochin ${ }^{1}$, Kay J Park ${ }^{1}$, Satish K Tickoo, Victor E Reuter and Hikmat Al-Ahmadie \\ Memorial Sloan-Kettering Cancer Center, Department of Pathology, New York, NY, USA
}

\begin{abstract}
Squamous cell carcinomas of the urinary bladder are rare in the Western world; the majority of cases are reported in countries endemic to Schistosoma parasitic infections. Unlike squamous tumors of the uterine cervix or oropharynx, the human papillomavirus (HPV) is not commonly associated with bladder squamous cell carcinomas. We report on two cases of HPV-positive urothelial carcinomas of the urinary bladder with extensive squamous differentiation showing the typical basaloid, poorly differentiated morphology of HPV-associated tumors. These occurred in patients with neurogenic bladders who had long-standing histories of selfcatheterization with tumors that tested positive for HPV by in situ hybridization. A retrospective review of our institutional database revealed four additional patients with bladder tumors showing squamous differentiation arising in the setting of neurogenic bladder. Review of these cases showed the more common welldifferentiated keratinizing appearance of squamous cell carcinomas of the bladder. These tumors showed only patchy positivity for p16 immunohistochemical stain (not the diffuse strong staining seen in HPV-positive tumors), and the one tested case was negative for HPV by in situ hybridization. HPV infection and neurogenic bladder have been independently associated with increased risk of developing carcinoma in the urinary bladder; however, this is the first report of squamous tumors arising in the setting of concurrent neurogenic bladder and HPV infection. The morphology of these tumors is similar to that of other high-risk HPV-associated squamous carcinomas with a basaloid, poorly differentiated appearance and little to no keratin formation. Modern Pathology (2012) 25, 1534-1542; doi:10.1038/modpathol.2012.112; published online 6 July 2012
\end{abstract}

Keywords: HPV; neurogenic bladder; squamous cell carcinoma; urothelial cancer

The human papillomavirus (HPV) has an important role as a human carcinogen, with an estimated $10 \%$ of cancers worldwide attributed to it. ${ }^{1} \mathrm{HPV}$ is a small circular double-stranded DNA virus with more than 100 different types described to date. ${ }^{2}$ The potential of the virus to cause malignant or benign lesions dictates its classification into low-risk $(6,11,40,42$, and so on) or high-risk (16, $18,31,33,45,51$, and so on) types. The prototypical model for carcinogenesis is squamous cell carcinoma of the uterine cervix, in which nearly all such

Correspondence: Dr KJ Park, MD, Memorial Sloan-Kettering Cancer Center, Department of Pathology, 1275 York Avenue, New York, NY 10065, USA.

E-mail: gynbreast@mskcc.org

${ }^{1}$ These authors contributed equally to this work.

Received 10 February 2012; revised 11 May 2012; accepted 14 May 2012; published online 6 July 2012 carcinomas are associated with HPV infection., ${ }^{3,4}$ The oncogenic role of HPV is also well established for a subset of squamous cell carcinomas in the vulva, ${ }^{5}$ penis, ${ }^{6}$ anus,${ }^{7}$ and oropharynx. ${ }^{8}$ The possible role of HPV infection in bladder tumors has not been completely elucidated as HPV detection rates vary widely from 0 to $100 \%$, depending on the study. ${ }^{9,10}$

An intriguing issue has been the possible association of the virus with bladder squamous cell carcinoma. The few published studies ${ }^{11-14}$ on this relationship have shown a low frequency of HPV detection, implying that HPV is not likely to have a major role in the development of bladder squamous cell carcinoma. However, the positive cases identified in the literature suggest that under certain circumstances, such as immunosuppression ${ }^{12}$ and persistent condylomatous infection, ${ }^{11,15,16}$ the virus may exert its oncogenic activity in the bladder. 
Interestingly, both low- ${ }^{17}$ and high-risk ${ }^{18}$ HPV types have been detected in bladder condylomas. While the causative role of HPV infection in bladder cancer remains to be fully elucidated, several other factors have been implicated in its carcinogenesis. Among these are smoking, arsenic and aromatic amines exposure, ${ }^{19}$ and chronic irritation associated with Schistosoma parasites, chronic urinary tract infection, and calculi. ${ }^{20}$

Conflicting results have been published on the association of spinal cord injury and bladder carcinomas. Some studies report a 16 - to 26 -fold increased risk of cancer, ${ }^{21,22}$ while other studies suggest that the risk is comparable to that of the general population. ${ }^{23,24}$ Nevertheless, all groups convincingly show that squamous cell carcinoma of the bladder is overrepresented in this category of patients, comprising $19 \%{ }^{23}$ to $46.9 \%^{21,22}$ of all bladder carcinomas; this is significantly higher than in the general population, where non-schistosomal squamous cell carcinoma constitutes only $1.3-3.2 \%$ of bladder cancer. ${ }^{11}$ It is believed that a significant subset of squamous cell carcinoma arises in a background of squamous metaplasia that develops secondary to irritation related to long-term catheterization and recurrent urinary tract infections associated with neurogenic bladder.

Concurrent HPV infection and prolonged catheterization in bladder cancer has not been previously reported. Here we describe two cases of HPVpositive bladder carcinomas with predominant squamous differentiation in female patients undergoing intermittent catheterization over an extended period of time due to neurogenic bladder.

\section{Materials and methods}

Two cases of HPV-positive bladder carcinoma were identified during routine histopathological evaluation at Memorial Sloan-Kettering Cancer Center. In each case, immunohistochemical stains for p16 as well as in situ hybridization for high-risk HPV were performed as part of the diagnostic work-up due to the unusual morphologic features of the tumors. Both patients had a long-standing history of neurogenic bladder. This prompted us to perform a retrospective search in the clinical database for bladder cancer with squamous differentiation in patients with a history of neurogenic bladder. A search was conducted for the period 2002-2011 and all cases meeting these criteria were submitted to pathological evaluation. Immunohistochemistry for p16 was performed on the initial two cases using the CINtec p16INK4a Histology kit developed by MTM Laboratories AG, Germany. The in situ hybridization probe for high-risk HPV was performed with the HPV III family 16 (high-risk probe) by Ventana (Ventana Medical Systems, Tucson, AZ) with appropriate controls.

\section{Results}

\section{Patient 1}

A 44-year-old woman presented in February 2010 for evaluation of pelvic pain and hematuria. Her past medical history was significant for lipomeningomyelocele requiring laminectomy at the age of 5 years. She had been using clean intermittent catheterization in the range of 15 to 20 times a day since a very young age. She also reported frequent urinary tract infections. The patient underwent vaginal hysterectomy for prolapse in 2009 with no other pertinent gynecologic history, and there was no specific mention of any previous Pap smear results in this patient. The pelvic pain was felt to be secondary to vaginal wall prolapse; however, an ultrasound showed a bladder abnormality. On cystoscopy, the entire mucosa was white and covered with plaques, and a nodular invasive tumor was identified. The patient underwent a transurethral resection of bladder tumor and two subsequent biopsies. Histological sections from the transurethral resection of bladder tumor showed detached fragments of invasive and in situ urothelial carcinoma and squamous cell carcinoma. The invasive component was poorly differentiated and composed of small basaloid cells without prominent keratinization. A spectrum of squamous epithelial atypia was observed in the overlying squamous mucosa equivalent to what would be considered moderateto-severe dysplasia in the uterine cervix. Koilocytic changes were also noted in the superficial layers of the squamous mucosa. Almost the entire mucosal surface of the bladder showed either squamous metaplasia or squamous dysplasia with very little native urothelium present. The non-neoplastic mucosa (both squamous and urothelial) was negative for p16 and HPV in situ hybridization.

The patient received neoadjuvant treatment with gemcitabine and cisplatinum followed by cystectomy with partial vaginectomy and bilateral salpingo-oophorectomy. On gross examination the tumor was identified as a $2.0 \times 1.7 \mathrm{~cm}$ hemorrhagic ulcerated lesion located on the posterior wall and dome of the bladder. Microscopically, the tumor was almost exclusively non-keratinizing squamous cell carcinoma with only focal areas of keratinization invading into the deep muscularis propria and perivesical soft tissue (pathological stage T3; Figure 1). Perineural and vascular invasion were not identified. The urothelium exhibited diffuse squamous features with a basaloid appearance, disordered maturation, loss of polarity, and scattered large atypical cells involving the full thickness of the mucosa consistent with high-grade squamous intraepithelial lesion/carcinoma in situ (Figure 1). The same findings were present in bilateral ureters. Vaginal tissue present in the specimen was unremarkable and did not show any signs of viral cytopathic effect. Immunohistochemical studies for 

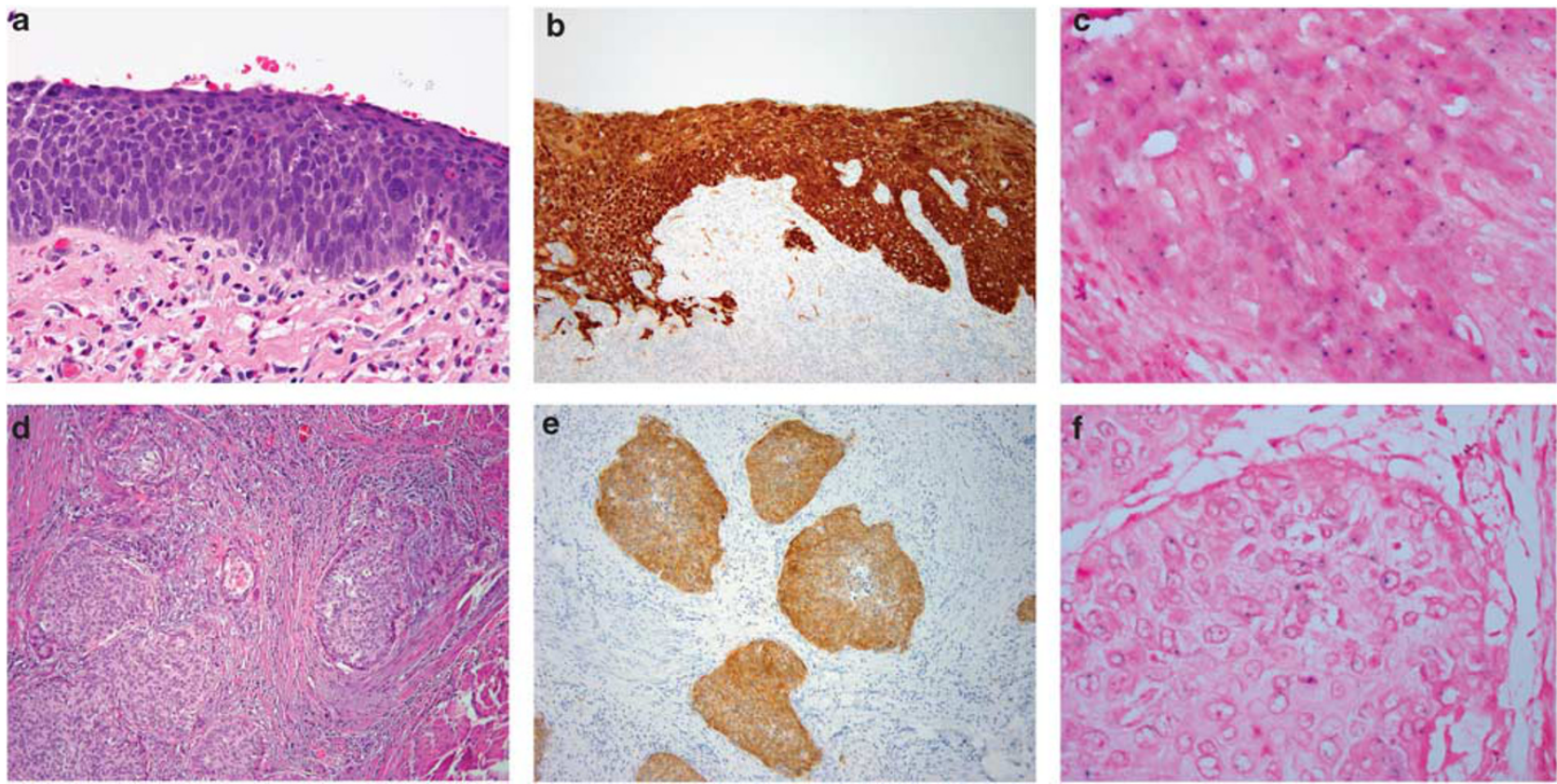

Figure 1 Patient 1: (a) in situ squamous cell carcinoma of bladder resembling high-grade squamous intraepithelial lesion of uterine cervix. (b) Invasive and in situ squamous cell carcinoma showing diffuse p16 positivity. (c) Positive HPV in situ hybridization of noninvasive disease showing punctate integrated pattern of staining. (d) Invasive squamous cell carcinoma of bladder with focal keratinization, deeply muscle invasive. (e) Invasive carcinoma with diffusely positive p16. (f) Positive HPV in situ hybridization of invasive component showing punctate integrated pattern of staining.

p16 showed diffuse strong cytoplasmic and nuclear staining in both the in situ and invasive components (Figure 1). In situ hybridization analysis for highrisk HPV revealed dot-like nuclear labeling in the majority of the invasive carcinoma cells and was seen to a much lesser extent in the in situ component (Figure 1). Diffuse nuclear staining, characteristic of the episomal state of the virus, was not seen.

As of the most recent follow-up appointment in February 2012, the patient has no evidence of disease.

\section{Patient 2}

A 48-year-old woman presented with hematuria to her local urologist. Her past medical history was significant for paraplegia below T8 after a motor vehicle accident at the age of 23 years. No gynecologic history was reported and specifically, there was no mention of any history of abnormal Pap smears. In 2000, the patient underwent bladderintestinal augmentation cystoplasty with Mitrofanoff appendicovesicostomy. She had been performing clean intermittent catheterization through the Mitrofanoff canal ever since, complicated by chronic urinary tract infections and development of small bladder capacity. Cystoscopy revealed a tumor that appeared to be limited to the bladder augmentation pouch. Two biopsies from the pouch were performed. The biopsied specimens were histologically similar to those of Patient 1: they were characterized by invasive urothelial carcinoma with squamous, basaloid, and glandular differentiation, including signet ring cells. The in situ component was represented predominantly by squamous carcinoma in situ with a small focus of flat (in situ) urothelial carcinoma. The non-neoplastic urothelium was diffusely involved by squamous metaplasia. The invasive tumor extended into the lamina propria and foci suspicious for lymphovascular invasion were identified. p16 immunohistochemical stain showed diffuse weak cytoplasmic and nuclear staining in the in situ and invasive components. HPV in situ hybridization had distinct dot-like nuclear positivity in the invasive part of the tumor and episomal-type nuclear staining in the squamous metaplastic mucosa with low-grade dysplasia. Similar patterns of labeling were seen in both the squamous and glandular components of the tumor. Uninvolved glandular epithelium of the intestinal tissue did not show any staining. Two months after the biopsies, the patient underwent surgical resection including cystectomy, hysterectomy with bilateral salpingo-oophorectomy, and partial vaginectomy. Gross examination revealed a $3.0 \times 1.1 \times$ $0.3 \mathrm{~cm}$ tan-white firm lesion in the right lateral wall of the neobladder. Microscopically, the bladder was composed of native urothelium and intestinal-type tissue consistent with the augmentation pouch. Squamous cell carcinoma in situ as well as metaplastic squamous epithelium extensively involved the urothelial/intestinal mucosa (Figure 2). Glandular dysplasia/adenocarcinoma in situ was not 

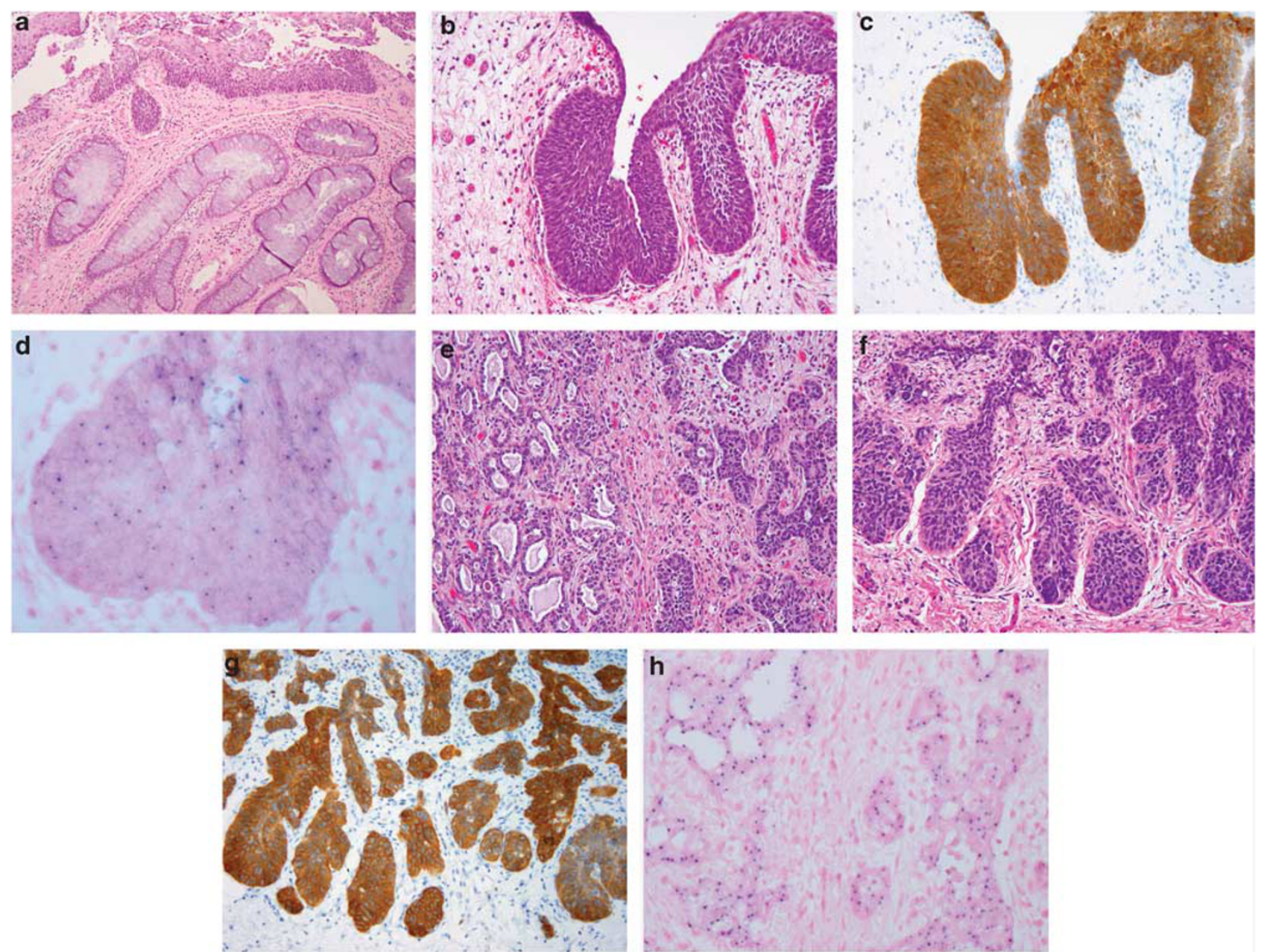

Figure 2 Patient 2: (a) in situ squamous cell carcinoma involving augmented intestinal portion of neobladder. Underlying benign intestinal glands are present. (b) In situ squamous cell carcinoma of bladder resembling high-grade squamous intraepithelial lesion of uterine cervix. (c) Diffusely positive p16 staining of in situ squamous cell carcinoma. (d) Positive HPV in situ hybridization of in situ carcinoma, showing punctate integrated pattern of staining. (e) Invasive urothelial carcinoma with squamous and glandular differentiation. (f) Invasive squamous cell carcinoma component of tumor. (g) Diffusely positive p16 staining of invasive carcinoma. (h) Positive HPV in situ hybridization of invasive squamous and glandular components of the tumor, showing punctate integrated pattern of staining.

apparent. The invasive carcinoma was localized to the urothelial-intestinal junction and was represented predominantly by basaloid non-keratinizing squamous cell carcinoma growing in an infiltrative pattern. A separate focus of invasive adenocarcinoma composed of small- to intermediate-sized cystic spaces lined by a single layer of cuboidal cells was present underneath an area of squamous cell carcinoma in situ (Figure 2). The tumor extended into the left ureter, deep muscularis propria, and perivesical soft tissue (pathological stage T3). Perineural and vascular invasion were not identified. Non-neoplastic mucosa showed diffuse squamous metaplasia in the urothelium and ulceration of the intestinal graft. p16 and HPV in situ hybridization were negative in the non-neoplastic urothelium and intestinal glands. The entire cervix was coned and submitted for histological evaluation and showed no evidence of dysplasia. Vaginal tissue was also unremarkable. p16 immunohistochemical stain showed diffuse strong cytoplasmic and nuclear labeling in the in situ squamous cell carcinoma and weak positivity in both the squamous and glandular invasive carcinoma (Figure 2). HPV DNA was shown to be present by in situ hybridization analysis in the in situ and invasive areas (Figure 2). As of the most recent follow-up in April 2012, the patient had no evidence of disease.

A retrospective analysis of 250 cases of urothelial carcinoma with squamous differentiation or pure squamous cell carcinoma of the bladder revealed four patients with a history of neurogenic bladder. Two patients had been undergoing clean intermittent catheterization, one since 1985 following a motor vehicle accident and one since 1986 due to multiple sclerosis. Another patient had been selfcatheterizing two to three times a day since 1998 following surgery for endometriosis. The fourth 
patient had a clinical picture of neurogenic bladder of uncertain etiology that did not require catheterization. Microscopically, the tumors were composed entirely of squamous cell carcinoma (two cases) or exhibited a prominent squamous cell carcinoma component in an otherwise usual type of urothelial carcinoma. In all four cases, the tumors showed prominent keratinization without the more basaloid appearance seen in our two study cases. p16 immunohistochemical stain showed patchy positivity in one case where it focally labeled urothelial carcinoma in situ as well as areas of invasive squamous cell carcinoma. HPV in situ hybridization in this case was negative.

\section{Discussion}

The association of HPV and tumors in the bladder has been previously reported for benign and malignant lesions, but, true HPV-driven carcinogenesis of bladder is rare, with only a few cases reported in the literature. The association of squamous cell carcinoma and neurogenic bladder has also been described, but this may be a function of the indwelling catheters that are frequently used in these patients. We report on two patients with neurogenic bladder who developed urothelial carcinoma with prominent squamous differentiation displaying morphological features similar to HPVassociated squamous cell carcinoma of the uterine cervix and that were positive for high-risk HPV by in situ hybridization. We found no such association in four additional cases associated with neurogenic bladder.

HPV is a non-enveloped, circular, doublestranded DNA virus of approximately $8 \mathrm{~kb}$, which has been implicated in the development of up to $10 \%$ of cancers worldwide. ${ }^{1,4}$ It belongs to the Papillomaviridae family of viruses and is classified into low-risk and high-risk groups based on the ability to cause malignant transformation. At present, there are over 100 types of papillomaviruses that have been described; new variants are classified when the sequence of the L1 gene is at least $10 \%$ dissimilar from any previously described variant. The oncogenic activity of the virus is dependent on the E6 and E7 early viral proteins, which have a major role in malignant transformation by disrupting cell cycle regulation by p53 and the retinoblastoma protein (pRB), respectively. Additionally, HPV targets other important molecules such as c-Myc, hTERT, ${ }^{25,26}$ PDZ-containing proteins, ${ }^{27}$ and tuberin, ${ }^{28}$ leading to overall genomic instability. ${ }^{29}$ HPV is exclusively epitheliotropic. It is a unique virus that does not bind directly to intact epithelia, but rather requires conformational change at the extracellular basement membrane prior to cellular attachment. $^{30}$ This mechanism of entry most likely explains the propensity of the virus to infect the cervical transformation zone, where the basement membrane is frequently exposed, as well as other sites of chronic inflammation with epithelial microtrauma. Once the virus is in the basal keratinocytes, its replication is coupled to host cell division. To exert its oncogenic potential the virus must be integrated into the host DNA; this usually occurs after long, persistent infections. ${ }^{31}$ The role of HPV has been well established for carcinomas of the cervix, vulva, ${ }^{5}$ penis, ${ }^{6}$ anus, ${ }^{7}$ and oropharynx. ${ }^{20}$ Most of these tumors are of squamous histology with the exception of cervical adenocarcinoma, and these HPV-associated squamous cell carcinomas of different anatomic locations commonly share basaloid or warty morphology.

The majority of HPV infections resolve spontaneously with the help of the innate immune system. ${ }^{2}$ In patients with immunosuppression, HPV-associated carcinomas are seen at increased frequency, with cervical carcinoma regarded as one of the Acquired Immunodeficiency Syndromedefining illnesses. ${ }^{32,33}$ Cumulative knowledge about HPV-associated cancers allowed for defining a set of criteria that needs to be met in order for the tumor to be considered HPV-driven. Among these criteria are (1) localization of the virus to the nucleus and (2) the presence of virus in the full spectrum of disease from benign/low-grade lesions to high-grade lesions and invasive carcinomas. Detection of the virus in cervical adenocarcinoma suggests that the transforming activity of the virus is not limited to squamous epithelium. ${ }^{34}$

Both high-risk ${ }^{18}$ and low-risk ${ }^{15,17}$ types of HPV have been detected in condylomata of the bladder. Although these are rare and generally regarded as benign lesions, several studies have shown squamous cell carcinoma arising in the background of condylomata. ${ }^{11,16,17,35}$ It is important to note that patients in these studies were either chronically immunosuppressed ${ }^{11,17}$ or showed persistent condylomatous infection with ${ }^{11}$ or without ${ }^{16}$ associated extensive vaginal condylomata. Inverted papillomas of the bladder have also been examined for HPV with variable results. Gould et $a{ }^{36}$ reported that out of 18 cases, only 1 was positive for HPV 11 (9\%), but in a study by Shigehara et $a l,{ }^{37}$ DNA from HPV 16 and 18 was identified in 7 out of 8 cases $(87.5 \%)$ by polymerase chain reaction (PCR) and confirmed by in situ hybridization analysis. Reported HPV rates also vary widely for invasive urothelial carcinomas, ranging from 0 to $100 \% .^{38-40}$ This variation may be due to the different methods of detection used in the studies. For frozen or fresh tissue, PCR is considered to be the gold standard, ${ }^{41}$ although PCR technique is frequently blamed for being oversensitive, subject to contamination, and false-positive results. When interpreting PCR results, it is important to note the strength of the signal, as it is required to have at least one viral copy per cell for transformation. In situ hybridization, although not as sensitive as PCR, has been widely applied ${ }^{42}$ with the important advantage of direct visualization of the virus in the cell and 
evaluation of the episomal versus integrated state of the viral DNA. ${ }^{43,44}$ The optimal detection method, however, still remains unclear and is likely a combination of both molecular detection and direct visualization.

The majority of published studies on bladder urothelial carcinomas use PCR, while some rely on Southern blot analysis for the isolation of the viral capsid or serological testing for antiviral antibody. The use of different techniques and the type of tissue (frozen vs paraffin-embedded) does not fully account for the variability in detection rates. High prevalence of HPV has been shown not only in studies relying solely on PCR, ${ }^{39,45}$ but also in studies where PCR was combined with Southern blot, ${ }^{9,46}$ dot blot hybridization, ${ }^{47}$ or in situ hybridization. ${ }^{48,49}$ Other studies using the same methods yielded much lower rates of detection. ${ }^{10,12,50-53}$ Unfortunately, it is difficult to interpret the results because not all studies have analyzed non-lesional bladder tissue as control. For example, Anwar et $a l^{9}$ detected the virus in $33 \%$ of healthy bladders, in contrast to Tekin, ${ }^{53}$ who did not detect it in any of the 10 control cases. Smetana et $a{ }^{49}{ }^{49}$ on the other hand, showed the virus in 2 out of 41 samples of nonlesional tissue from the same patients. Regional location does not seem to explain the inconsistencies either. For example, two Japanese groups were among the ones to report both high prevalence and absence of HPV in bladder carcinoma. In a study by Shigehara et al, ${ }^{13}$ high-risk HPV DNA was detected in 18 of 117 patients (15\%), while Sano et al ${ }^{54}$ failed to identify any HPV DNA in their study.

Squamous cell carcinoma of the bladder in particular has also been analyzed in a number of studies. $^{12-14}$ Maloney et $a l^{12}$ showed the presence of HPV 18 by PCR in 1 of 22 patients (4.5\%) with squamous cell carcinoma while Shigehara et $a l^{13}$ and Westenend et al $^{14}$ did not identify HPV in any of their 4 and 16 cases, respectively.

In clinical practice, p16 is increasingly being used as a surrogate marker for high-risk HPV infection. p16 is a product of the INK $4 a$ gene on chromosome 9 (9p21) and belongs to a family of tumor suppressor proteins involved in cell cycle regulation. It executes its function by suppressing cyclin-dependent kinase-mediated phosphorylation of $\mathrm{pRb}$ to control the cell cycle at the G1-S interphase. In infected cells, the HPV E7 oncoprotein binds and degrades host $\mathrm{pRb}$ leading to uncontrolled overexpression of p16. ${ }^{55,56}$ While strong and diffuse cytoplasmic and nuclear p16 expression has been shown to correlate well with HPV status in the cervix ${ }^{57-59}$ and vulva, ${ }^{60}$ it does not appear to have the same predictive value in bladder carcinomas. Cioffi-Lavina et $a l^{61}$ have shown p16 overexpression in 14 out of 38 cases $(37 \%)$ of bladder squamous cell carcinoma. It is likely that other, non-HPV-related mechanisms are responsible for upregulation of p16 in these cases. In fact, non-HPV-associated p16 overexpression is well established in other tumor types, such as uterine and ovarian serous carcinomas and nonHPV-associated cervical adenocarcinomas. ${ }^{26,62}$

The two patients in our study had histories of neurogenic bladder and prolonged catheterization with chronic urinary tract infections, which by themselves are well-established risk factors for the development of bladder squamous cell carcinoma. To our knowledge, this is the first report of HPVassociated bladder carcinoma arising in this setting. Conflicting data exist in the literature regarding the risk of bladder cancer in patients with spinal cord injury and neurogenic bladder. The incidence varies from $0.39 \%,{ }^{24}$ which is comparable to the general population, to $2.4 \% .{ }^{22}$ While the rates of carcinoma vary substantially, all studies showed a strong association of prolonged catheterization with squamous cell carcinoma and adenocarcinoma of the bladder. ${ }^{21-24}$ It is believed that squamous cell carcinoma arises through squamous metaplasia secondary to long-term irritation associated with catheterization and recurrent urinary tract infections. ${ }^{63}$ Development of adenocarcinoma is less well understood.

Basaloid and warty morphologies are characteristic of HPV-associated squamous cell carcinomas and have been shown to correlate with viral status in oropharyngeal, ${ }^{8}$ vulvar, ${ }^{5}$ penile, ${ }^{38}$ and anal carcinomas. ${ }^{53}$ Bladder squamous cell carcinoma very rarely shows basaloid/warty features, which is consistent with the infrequent finding of HPV in bladder squamous cell carcinoma. In fact, it was these morphological features that lead us to perform HPV studies initially. Results of our retrospective analysis confirm the observation. We failed to demonstrate HPV infection in tumors that displayed overt keratinization and did not show basaloid morphology. Aside from our two case studies with a prominent basaloid component, only four such case reports of basaloid squamous cell carcinoma of the urinary tract were found in the English literature. ${ }^{64,65}$ Vakar-Lopez and Abrams ${ }^{65}$ reported a 60-year-old woman who had developed urinary tract incontinence in her $40 \mathrm{~s}$ due to multiple vaginal deliveries complicated by chronic urinary tract infections and multiple corrective surgeries. The cystectomy specimen contained extensive invasive squamous cell carcinoma with a microscopic component of urothelial cell carcinoma, while the uninvolved urothelium showed squamous metaplasia. Interestingly, in situ hybridization for low-risk and high-risk HPV was positive in the areas of squamous metaplasia, but not in the basaloid nests. The second case, reported by Neves et $a l^{64}$ featured a 54-year-old man with basaloid carcinoma of the bladder associated with a minor small-cell neuroendocrine carcinoma component arising in the background of squamous metaplasia, dysplasia, and carcinoma in situ. Of note, the patient had a history of long-standing neurogenic bladder with frequent urinary tract infections secondary to multiple sclerosis. In another case it occurred in the renal pelvis and was associated with a 
small-cell carcinoma, while the other arose in the ureter and was associated with a sarcomatous component, consistent with carcinosarcoma. ${ }^{66,67}$ However, no HPV studies were performed in the latter three cases.

Neither one of our patients had documented genital involvement by HPV. Portions of the vaginal tissue submitted with the cystectomy specimens did not show any morphological evidence of viral cytopathic effect in either patient. It is conceivable and likely that the patients had an HPV infection in the genital tract at some point in their lives as HPV is the most ubiquitous sexually transmitted infection with approximately $80 \%$ of sexually active individuals harboring the virus during their lifetime. ${ }^{68}$ The virus was then either directly inoculated into the bladder urothelium in the process of catheterization or was transferred by route of ascending infection. Frequent catheterizations over an extended period of time likely contributed to the recurrent infections and irritation of the bladder leading to loss of urothelial integrity and development of squamous metaplasia. Such an environment could be seen as analogous to the transformation zone of the cervix, where there is a continuous substitution of glandular epithelium by squamous cells in response to trauma and infection. In this process, the basement membrane becomes intermittently exposed and serves as an effective binding site for HPV virions, where they undergo conformational change allowing them to enter the basal keratinocytes. The development of an HPV-positive glandular component (adenocarcinoma) in patient 2 is intriguing and could be similar to the process of urothelial tumorigenesis, where glandular-type divergent differentiation is a known phenomenon. The possibility that this adenocarcinoma arose from the intestinal epithelium (appendix) is unlikely due to the absence of HPV DNA in the uninvolved intestinal mucosa. It is more likely that both squamous and glandular components represent divergent differentiation of one histogenesis driven by integrated HPV.

In conclusion, we report two cases of urothelial carcinoma with prominent squamous differentiation associated with high-risk HPV arising in the setting of recurrent urinary tract infections and squamous metaplasia secondary to neurogenic bladder and prolonged catheterization. We hypothesize that repeated catheterization may have an important role in the viral transformation of the epithelium by creating an environment analogous to the cervical transformation zone. Our inability to identify HPV infection in four patients presenting in a similar clinical setting of neurogenic bladder, but with squamous cell carcinoma with prominent keratinization, indicates that urothelial and squamous tumorigenesis in this setting is not exclusive to HPV effect. It is possible that the basaloid morphology may be an important indicator of the viral status in the bladder as it is in other organs. Validation of this hypothesis requires future studies directed at the patient population undergoing bladder catheterization.

\section{Disclosure/conflict of interest}

The authors declare no conflict of interest.

\section{References}

1 Parkin DM, Bray F. Chapter 2: the burden of HPVrelated cancers. Vaccine 2006;24(Suppl 3):11-25.

2 Narisawa-Saito M, Kiyono T. Basic mechanisms of high-risk human papillomavirus-induced carcinogenesis: Roles of E6 and E7 proteins. Cancer Sci 2007;98:1505-1511.

3 McLaughlin-Drubin ME, Munger K. Viruses associated with human cancer. Biochim Biophys Acta 2008;1782: 127-150.

4 Stanley M. Pathology and epidemiology of HPV infection in females. Gynecol Oncol 2010;117:S5-S10.

5 van der Avoort IAM, Shirango H, Hoevenaars BM, et al. Vulvar squamous cell carcinoma is a multifactorial disease following two separate and independent pathways. Int J Gynecol Pathol 2006;25:22-29.

6 Miralles-Guri C, Bruni L, Cubilla AL, et al. Human papillomavirus prevalence and type distribution in penile carcinoma. J Clin Pathol 2009;62:870-878.

7 Delbello A, Colli C, Martinez Tdel R, et al. Anal canal and rectal condylomatosis: exhaustive proctological examination and STD patients. Acta Dermatovenerol Alp Panonica Adriat 2010;19:13-16.

8 Lewis J, Thorstad W, Chernock R, et al. p16 positive oropharyngeal squamous cell carcinoma: an entity with a favorable prognosis regardless of tumor HPV status. Am J Surg Pathol 2010;34:1088-1096.

9 Anwar K, Naiki H, Nakakuki K, et al. High frequency of human papillomavirus infection in carcinoma of the urinary bladder. Cancer 1992;70:1967-1973.

10 Aynaud O, Tranbaloc P, Orth G. Lack of evidence for a role of human papillomaviruses in transitional cell carcinoma of the bladder. J Urol 1998;159:86-89; discussion 90.

11 Guo CC, Fine SW, Epstein JI. Noninvasive squamous lesions in the urinary bladder: a clinicopathologic analysis of 29 cases. Am J Surg Pathol 2006;30: 883-891.

12 Maloney KE, Wiener JS, Walther PJ. Oncogenic human papillomaviruses are rarely associated with squamous cell carcinoma of the bladder: evaluation by differential polymerase chain reaction. J Urol 1994;151: 360-364.

13 Shigehara K, Sasagawa T, Kawaguchi S, et al. Etiologic role of human papillomavirus infection in bladder carcinoma. Cancer 2011;117:2067-2076.

14 Westenend PJ, Stoop JA, Hendriks JG. Human papillomaviruses 6/11, 16/18 and 31/33/51 are not associated with squamous cell carcinoma of the urinary bladder. BJU Int 2001;88:198-201.

15 Bruske T, Loch T, Thiemann O, et al. Panurothelial condyloma acuminatum with development of squamous cell carcinoma of the bladder and renal pelvis. J Urol 1997;157:620-621.

16 Lagwinski N, Thomas A, Stephenson A, et al. Squamous cell carcinoma of the bladder: a clinicopatho- 
logic analysis of 45 cases. Am J Surg Pathol 2007;31: 1777-1787.

17 Del Mistro A, Koss LG, Braunstein J, et al. Condylomata acuminata of the urinary bladder. Natural history, viral typing, and DNA content. Am J Surg Pathol 1988;12:205-215.

18 Chrisofos M, Skolarikos A, Lazaris A, et al. HPV 16/18associated condyloma acuminatum of the urinary bladder: first international report and review of literature. Int J STD AIDS 2004;15:836-838.

19 Kakehi Y, Hirao Y, Kim W, et al. Bladder cancer working group report. Jpn J Clin Oncol 2010;40(Suppl 1): i57-i64.

20 Shokeir AA. Squamous cell carcinoma of the bladder: pathology, diagnosis and treatment. BJU Int 2004;93: 216-220.

21 Hess MJ, Zhan EH, Foo DK, et al. Bladder cancer in patients with spinal cord injury. J Spinal Cord Med 2003;26:335-338.

22 Kalisvaart JF, Katsumi HK, Ronningen LD, et al. Bladder cancer in spinal cord injury patients. Spinal Cord 2010;48:257-261.

23 Pannek J. Transitional cell carcinoma in patients with spinal cord injury: a high risk malignancy? Urology 2002;59:240-244.

24 West DA, Cummings JM, Longo WE, et al. Role of chronic catheterization in the development of bladder cancer in patients with spinal cord injury. Urology 1999;53:292-297.

25 McMurray HR, McCance DJ. Human papillomavirus type 16 E6 activates TERT gene transcription through induction of c-myc and release of USF-mediated repression. J Virol 2003;77:9852-9861.

26 Veldman T, Liu X, Yuan $\mathrm{H}$, et al. Human papillomavirus E6 and myc proteins associate in vivo and bind to and cooperatively activate the telomerase reverse transcriptase promoter. Proc Natl Acad Sci USA 2003;100:8211-8216.

27 Lee SS, Glaunsinger B, Mantovani F, et al. Multi-PDZ domain protein MUPP1 is a cellular target for both adenovirus E4-ORF1 and high-risk papillomavirus type 18 E6 oncoproteins. J Virol 2000;74:9680-9693.

28 Shai A, Brake T, Somoza C, et al. The human papillomavirus E6 oncogene dysregulates the cell cycle and contributes to cervical carcinogenesis through two independent activities. Cancer Res 2007;67: 1626-1635.

29 Korzeniewski N, Spardy N, Duensing A, et al. Genomic instability and cancer: lessons learned from human papillomaviruses. Cancer Lett 2011;305:113-122.

30 Schiller J, Day P, Kines R. Current understanding of the mechanism of HPV infection. Gynecol Oncol 2010;118: S12-S17.

31 Ibeanu OA. Molecular pathogenesis of cervical cancer. Cancer Biol Ther 2011;11:295-306.

32 Chaturvedi A, Madeleine M, Biggar R, et al. Risk of human papillomavirus-associated cancers among persons with AIDS. J Natl Cancer Inst 2009;101: 1120-1130.

33 Frisch M, Biggar RJ, Goedert JJ. Human papillomavirus-associated cancers in patients with human immunodeficiency virus infection and acquired immunodeficiency syndrome. J Natl Cancer Inst 2000; 92:1500-1510.

34 Gillison ML, Shah KV. Chapter 9: Role of mucosal human papillomavirus in nongenital cancers. J Natl Cancer Inst Monogr 2003;31:57-65.
35 Botella E, Burgus O, Navarro S, et al. Warty carcinoma arising in condyloma acuminatum of urinary bladder: a case report. Int J Surg Pathol 2000;8:253-259.

36 Gould VE, Schmitt M, Vinokurova S, et al. Human papillomavirus and p16 expression in inverted papillomas of the urinary bladder. Cancer Lett 2010;292: 171-175.

37 Shigehara K, Sasagawa T, Doorbar J, et al. Etiological role of human papillomavirus infection for inverted papilloma of the bladder. J Med Virol 2011;83:277-285.

38 Cubilla A, Lloveras B, Alejo M, et al. The basaloid cell is the best tissue marker for human papillomavirus in invasive penile squamous cell carcinoma: a study of 202 cases from paraguay. Am J Surg Pathol 2010;34: 104-114.

39 De Gaetani C, Ferrari G, Righi E, et al. Detection of human papillomavirus DNA in urinary bladder carcinoma by in situ hybridisation. J Clin Pathol 1999; 52:103-106.

40 Yavuzer D, Karadayi N, Salepci T, et al. Role of human papillomavirus in the development of urothelial carcinoma. Med Oncol 2011;28:919-923.

41 Kosel S, Burggraf S, Mommsen J, et al. Type-specific detection of human papillomaviruses in a routine laboratory setting-improved sensitivity and specificity of PCR and sequence analysis compared to direct hybridisation. Clin Chem Lab Med 2003;41:787-791.

42 Shi W, Kato H, Perez-Ordonez B, et al. Comparative prognostic value of HPV16 E6 mRNA compared with in situ hybridization for human oropharyngeal squamous carcinoma. J Clin Oncol 2009;27:6213-6221.

43 Biedermann K, Dandachi N, Trattner M, et al. Comparison of real-time PCR signal-amplified in situ hybridization and conventional PCR for detection and quantification of human papillomavirus in archival cervical cancer tissue. J Clin Microbiol 2004;42: 3758-3765.

44 Bryan JT, Taddeo F, Skulsky D, et al. Detection of specific human papillomavirus types in paraffinembedded sections of cervical carcinomas. J Med Virol 2006;78:117-124.

45 Yang H, Yang K, Khafagi A, et al. Sensitive detection of human papillomavirus in cervical, head/neck, and schistosomiasis-associated bladder malignancies. Proc Natl Acad Sci USA 2005;102:7683-7688.

46 Tenti P, Zappatore R, Romagnoli S, et al. P53 overexpression and human papillomavirus infection in transitional cell carcinoma of the urinary bladder: correlation with histological parameters. J Pathol 1996;178:65-70.

47 Chan KW, Wong KY, Srivastava G. Prevalence of six types of human papillomavirus in inverted papilloma and papillary transitional cell carcinoma of the bladder: an evaluation by polymerase chain reaction. J Clin Pathol 1997;50:1018-1021.

48 LaRue H, Simoneau M, Fradet Y. Human papillomavirus in transitional cell carcinoma of the urinary bladder. Clin Cancer Res 1995;1:435-440.

49 Smetana Z, Keller T, Leventon-Kriss S, et al. Presence of human papilloma virus in transitional cell carcinoma in Jewish population in Israel. Cell Mol Biol 1995;41:1017-1023.

50 Chang F, Lipponen P, Tervahauta A, et al. Transitional cell carcinoma of the bladder: failure to demonstrate human papillomavirus deoxyribonucleic acid by in situ hybridization and polymerase chain reaction. J Urol 1994;152:1429-1433. 
$51 \mathrm{Lu}$ QL, Lalani el-N, Abel P. Human papillomavirus 16 and 18 infection is absent in urinary bladder carcinomas. Eur Urol 1997;31:428-432.

52 Mvula M, Iwasaka T, Iguchi A, et al. Do human papillomaviruses have a role in the pathogenesis of bladder carcinoma? J Urol 1996;155:471-474.

53 Tekin MI, Tuncer S, Aki FT, et al. Human papillomavirus associated with bladder carcinoma? Analysis by polymerase chain reaction. Int J Urol 1999;6: 184-186.

54 Sano T, Sakurai S, Fukuda T, et al. Unsuccessful effort to detect human papillomavirus DNA in urinary bladder cancers by the polymerase chain reaction and in situ hybridization. Pathol Int 1995;45:506-512.

55 Hara E, Smith R, Parry D, et al. Regulation of p16CDKN2 expression and its implications for cell immortalization and senescence. Mol Cell Biol 1996;16:859-867.

56 Nevins JR. The Rb/E2F pathway and cancer. Hum Mol Genet 2001;10:699-703.

57 Keating JT, Cviko A, Riethdorf S, et al. Ki-67, cyclin E, and p16INK4 are complimentary surrogate biomarkers for human papilloma virus-related cervical neoplasia. Am J Surg Pathol 2001;25:884-891.

58 Klaes R, Benner A, Friedrich T, et al. p16INK4a immunohistochemistry improves interobserver agreement in the diagnosis of cervical intraepithelial neoplasia. Am J Surg Pathol 2002;26:1389-1399.

59 Murphy N, Ring M, Heffron CC, et al. p16INK4A, CDC6, and MCM5: predictive biomarkers in cervical preinvasive neoplasia and cervical cancer. J Clin Pathol 2005;58:525-534.
60 Riethdorf S, Neffen E, Cviko A, et al. p16INK4A expression as biomarker for HPV 16-related vulvar neoplasias. Hum Pathol 2004;35:1477-1483.

61 Cioffi-Lavina M, Chapman-Fredricks J, GomezFernandez C, et al. P16 expression in squamous cell carcinomas of cervix and bladder. Appl Immunohistochem Mol Morphol 2010;18:344-347.

62 Weiner DP. The prevalence and significance of Brunn's nests, cystitis cystica and squamous metaplasia in normal bladders. J Urol 1979;122:317-321.

63 Delnay KM, Stonehill WH, Goldman H, et al. Bladder histological changes associated with chronic indwelling urinary catheter. J Urol 1999;161:1106-1108.

64 Neves TR, Soares MJ, Monteiro PG, et al. Basaloid squamous cell carcinoma in the urinary bladder with small-cell carcinoma. J Clin Oncol 2011;29:440-e442.

65 Vakar-Lopez F, Abrams J. Basaloid squamous cell carcinoma occurring in the urinary bladder. Arch Pathol Lab Med 2000;124:455-459.

66 Hagemann IS, et al. Basaloid squamous carcinoma arising in (corrected) the renal pelvis. Int J Surg Pathol 2008;16:199-201.

67 Maeda D, Fujii A, Yamaguchi K, et al. Sarcomatoid carcinoma with a predominant basaloid squamous carcinoma component: the first report of an unusual biphasic tumor of the ureter. Jpn J Clin Oncol 2007;37: 878-883.

68 Syrjänen K, Hakama M, Saarikoski S, et al. Prevalence, incidence, and estimated life-time risk of cervical human papillomavirus infections in a nonselected Finnish female population. Sex Transm Dis 1990;17:15-19. 